\title{
Learning Through Experience: The Influence of Context on the Development of Rugby Coaches' Beliefs and Practice
}

\author{
Rémy Hassanin, Richard L. Light \\ School of Health Sciences, University of Ballarat, Australia \\ r.hassanin@ballarat.edu.au,r.light@ballarat.edu.au
}

\begin{abstract}
Aim. This article reports on a case study that inquired into how coaches' beliefs about and dispositions toward coaching that structure their practice were developed through long-term experience. Method. Focused on three coaches working at high performance levels in Victoria, Australia data was generated through three rounds of semi-structured interviews and observation over a three-month period. Results. The three coaches were from three diferent countries with the study highlighting the powerful influence of socio-cultural context on the construction of a coaching habitus and the ways in which it structurted their coaching.

Index Terms - Learning through experience, rugby coaches, beliefs and practice, experience
\end{abstract}

\section{Introduction}

Strategies prioritising rationalistic, non-problematic models of learning promoted in coaching [1] fail to encompass the complexity involved in learning how to coach [see for example 2, 3, 4, and 5] leading to claims that coaching is an art [6]. The sports coaching literature highlights the influence of experience on learning to coach $[7,8]$ but the effects of experience and the types of experiences that are most influential in developing coaching knowledge are not well understood. Within the context of growing interest in the sociological aspects of coaching and the influence of sociocultural context, Light [9] argues that developing coaching knowledge should be viewed as a social process.

Following on from this contention, this paper reports on a study that inquired into how coaches' beliefs about, and dispositions toward coaching that structure their practice were developed through long-term experience.

\section{A. Coach Development}

Tacit knowledge is the most powerful in structuring coaching practices [see for example 10,11, 12 and 13] and is developed non-consciously through experience. There is, however, only limited understanding of how this happens and little empirical research conducted on it. Light and Evans [11] argued that through engagement and participation in particular socio-cultural contexts a socialisation process occurs whereby knowledge is developed according to the fundamental beliefs of that particular social field (for example, sport) or sub-field (for example, rugby or rugby in a particular country). Such engagement forms and develops embodied knowledge of sports coaching that operates at a non-conscious level. Gergen [14] argues that the nature of such embodied knowledge, which develops through the experiences within a particular socio-cultural context, is embedded in cultural and historical meanings that shape one's beliefs. Further to this, Cushion et al. [15] argued that this is, indeed, the powerful influence of experience on structuring coaches' philosophies towards coaching. Nash et al. [16] argued that these philosophies form the underpinning beliefs of coaching that structure the practice of coaching. To this end Nash et al. [16] argue that these philosophies are strongly situated in 'life experiences' (p.536) with Lyle [8] suggesting that these are the sorts of beliefs which are expressed as the deeply held values that shape and structure coaching. These developments have been strongly influenced by the work of Bourdieu with his key analytic concepts; habitus in particular, is used as a conceptual tool to link past experiences to their current beliefs and practices [see for example, 10, 15, 17, 18, 19 and 20]

\section{B. Bourdieu and habitus}

Viewing coaching as a complex social practice has provided an opportunity to understand it as being socially and culturally situated [21]. Thus, coaching can be seen as a socially and culturally influenced system which Langer [22] suggests is, 'composed of individual members, has a structure, a history, a way of understanding the world and an institutional culture' [p. 72]. In this way, engagement in these fields develops perceptions and assumptions [23] as the powerful influence experience on developing philosophies of coaching that structure its practice [see for example, 10, 11 and 15].

\section{Methodology}

\section{A. Site and participants}

This case study forms part of a larger study comprising a total of six case studies conducted in Australia, South Africa and France. A selective/purposive sampling strategy [24] was used with participants for recruited from the highest club level of rugby in the state of Victoria, Australia. The names used in this paper are pseudonyms used to protect the participants' anonymity. The coaches were purposively sampled according to 2 criteria; they had to be head coach of the $1^{\text {st }}$ grade club team and coaching at the premier level. However, only upon the first meeting did it become apparent that these three coaches originated from three different socio-cultural contexts, which has since become a significant aspect of the study that highlighted the influence of the socio-cultural context in their beliefs, dispositions and practice. 
'Paul' was born in the late fifties and raised in Australia but only started playing rugby union at the age of 17 . He initially started with rugby league as it was one of the few sports available in his country town but went on to represent Australia in rugby union as a Wallaby. 'Mike' and 'Robert' had extensive playing careers and had early contact with rugby from the early age of five or six. Mike was born in the early seventies in New Zealand and played all his rugby there. After coaching for five seasons he moved to Australia seven years prior to the study. Robert was born in the mid sixties and played all of his rugby in South Africa. He retired in his early thirties and coached for two seasons in South Africa before moving to Australia a decade ago.

\section{B. Data generation}

Data were generated through observation and three rounds of interviews conducted over a three-month period. Observations. Data generation began with observations, which were noted in a research diary [25] and used to triangulate the interview data.

Interviews. Three, 60-90 minute, semi-structured interviews were conducted using a grounded theory approach [26] and Bourdieu's concept of habitus was used to generate data by following Lau's [27] suggestions, as applied in a study on rugby coaches by Light and Evans [11]. Interview one had a general structure inquiring into beliefs about coaching as adapted from Evans [28] study. Interview two was designed to further investigate themes that were emerging from the initial analysis of interview one and the observations. Interview three followed a life history approach [29] used to gain an understanding of the participants' lived histories in rugby. These were aimed at linking their thoughts and beliefs with significant experiences and periods of time.

The interviews were audio recorded and transcribed verbatim. They inquired into the influences of significant people, experiences and the socio-contexts, using probes and follow up questions to provide richer descriptions, such is the significance placed on qualitative work in getting close to the data [25]. Questions from Evans [28] study were adapted to the interview in order to identify features of a coaching habitus. These were principally focused on inquiring into their views on 1) What is good coaching? 2) What makes a good coach? 3) What is a good player? and, 4) What is a coach's responsibility?

\section{Data analysis}

All interviews were read and re-read with an initial coding stage to identify categories and emergent themes that were tested and modified over each round of interviews. From this the interviews were compared using the constant comparative method [26]. The significance of the sociocultural influence of the views and beliefs of coaches became evident when the voice seemed almost unique.

\section{Results}

The coaches in this study all had distinctly different backgrounds and experiences. They also grew up playing rugby and began coaching in three different countries so it is not surprising that they all had very different habitus that are identified in this section of the article. This study did, however, identify one common theme across the habitus of all three coaches and this was their sets of beliefs associated with the ideals of amateurism.

\section{A. The influence of the ideals of amateurism}

The powerful influence of beliefs associated with the amateur ideals of rugby formed a strong theme across all three coaches. The amateur ideal had a profound influence on rugby's practice and meaning up until the advent of professionalism in 1995 and all three coaches had spent their formative years in rugby before professionalism. Despite the quite different backgrounds of the three coaches they all shared a common belief in the values and ideals of amateurism. This included the belief that rugby should promote fair play and other moral and ethical behaviour [30]. They wanted to be successful coaches in terms of winning matches and championships but experienced some conflict between a pragmatic approach to winning and the value they attached to the way in which their teams won.

Whilst they acknowledge the pressure exerted from their clubs on them for results and their own desire to win there was tension between a 'win at all cost attitude' typically associated with professionalism and a belief in the important moral and ethical learning that rugby could and they felt, should, encourage. Such values featured very strongly when asked their views on good coaching such as with Mike:

I think what makes great coaching is a team feeling like they're in a
different place and a better place than they were at the start of the year
compared to the end of the year...so the best compliment I can have is
not a player coming up and saying thanks coach we won. The best
compliment I can get is a player that comes up and says thanks coach I
look at things a lot differently than what I did before, and I have this
complete new sense of belief in what I'm capable of, I think that's great
coaching because you know you're not making a great rugby player
you're making a great person, and great people make great rugby
players. (Mike, Int.2 13/09/2012) All three participants maintained a belief in the need for players to enjoy rugby and not merely see it as a job, which is more associated with the amateur, pre-professional era. This is made clear in the following quote from Robert:

I don't think coaching is rocket science I just think if you've got good people skills and if you have the interest of the players at heart that you'll go a long way. Bad coaches are driven for the wrong reasons and the right reasons are that; one you want to develop the players, two you want to make sure that when they get to the end of the season they can look back and say wow we had a good time. If you win some silverware that's even better but you don't want to win silverware at the expense of people saying fuck I didn't enjoy that. (Robert, Int.1 21/08/2012)

\section{B. Mike.}

Mike saw rugby as being far more than just a game. He deeply valued the ethical and moral learning that he felt rugby could and should develop in young men. His belief in this was so strong that it almost operated as a quazi-religion for him. In some ways the value he placed on player attitude and behaviour was similar to Roberts's emphasis on respect and commitment but it was more focused on learning life lessons through rugby. He was also clear in suggesting that this 
approach to rugby as a way of living life in New Zealand was rooted in Maori culture. This very significant influence on his coaching shaped the construction of his coaching habitus, through his participation in rugby in New Zealand as a player and then a coach. However, his agency as a businessman meant that it was overlaid by the values, beliefs and inclinations shaped by the doxa of the field of business. This then should be considered within the context of the sub-field of professional rugby as the product of the intrusion of the doxa of the field of business into the traditional field of sport as education. This makes an interesting mix of influences operating to shape the way in which Mike coaches.

Paul and Robert enjoyed friendly relationships with their players, exchanging jokes from time to time and valued being able to connect with their players but Mike was different in this regard. Mike as noted in my research diary was very precise, well organized, business-like and seemed to keep a professional distance with his players. This was strongly influenced by his involvement in business and his success in the business field. The construction of his coaching habitus had been strongly influenced by the culture of rugby in New Zealand but it had also been influenced by his experiences in business. Indeed, one motivation for getting involved in coaching rugby was to help him with his business career.

\section{Because business has been professional since it started, whereas like I've got a group of people that work for me at the moment and I can put my hand on my heart and say I care about all of them and when something happens at home or they get sick I want to make sure they are alright and just for very humanistic reasons. But at the same time I manage a professional distance with them because I need to perform at a certain level so that we get an output you know that is required (Int. 3, $22 / 11 / 2012$}

Although he values player empowerment the dichotomy between structure (business) and freedom (spiritual release of rugby) is a significant characteristic of Mike's coaching and habitus.

At the end of the day sports about a bunch of grown-ups running around after a ball and you can never lose sight of that. It's called playing rugby it's not called working rugby, and so we go out and we play and if you don't feel the exhilaration of just being involved well then you know we sort of failing (Int.2 13/09/2012)

However, his business values and the influence of the corporate environment contradicted these values that he believes have actually had a stronger influence on the way he coaches. Nevertheless, and quite possibly unconsciously, there was a strong recognition of play which seemed to be strongly linked to his early experiences in the sport when asked about his memories of rugby. Furthermore, the powerful link of rugby to the family have created this tension between freedom and framework when he states that his coaching philosophy is 'a term that I use, there is freedom in the framework.' (Int.116/08/2012)

When I think about the friends that I have now you know I'm sort of 40 and when I go back, I grew up in a small country town, bump into the guys that I grew up with. Well our conversations and our earliest memories are all related sport, you know so, can you remember when we went and played those guys, remember that time your dad spilled that pie down his shirts driving us to the game and nearly drove us into oncoming traffic you know... I suppose the earliest memories of it are, if
I was to sum it up, feelings of friendship and fun, sort of day out type feeling (Int.3 22/11/2012)

\section{Paul}

Paul grew up in rugby in Australia during an era that he describes as being distinctive and which he refers to as the “decision-making era”. He describes this era as being one in which Australian rugby emphasized creativity, flair and taking risks. He emphasised this by comparing it to the approach taken now by the Wallabies in the professional era that he felt was tentative and playing not to lose. He felt current approaches in Australia were too structured and coach dominated. His approach emphasised players learning through physical environments in which they felt free to experiment, take risks and learn to be creative thinkers in play.

Paul enjoyed and valued a 'warm' and friendly relationship with his players, they even called him by a nickname. Whether or not this is a feature of his easy-going coaching style [8] is uncertain but what is certain is that he placed great emphasis on empowering players, giving them autonomy and finding ways of developing them into better thinkers.

I'm more of a player-oriented coach whereby I give the players the skills
to be able to go onto the field and show them within the skills I do what
decisions they need to make to become better rugby players. I'm putting
the emphasis back on the players they're on the field I'm not, they're the
ones on the field who can read the plays and yell them my job is to get
them to do that (Int.2 13/09/2012)

When asked what he felt his responsibilities were as a coach they reflected his emphasis on decision-making, player empowerment and getting players to think for themselves. He said that he's trying to get players 'to start thinking about what [they're] doing. I don't want [them] to take it as gospel from me’ (Int. 2, 13/09/2012).

Paul wanted to take a player-centred approach and empower them to make good decisions on the field. He saw his role as providing learning environments in which his players found out for themselves and developed as better thinkers who could be independent from the coach during matches:

\begin{abstract}
I think the creation of environment where players can succeed, strive for success, strive to be better, more skilled, all that sort of stuff, all that to create a really, really good environment to want, to want to do it that's what I think a good coach can do... That's what you've got to do as a coach. (Paul, Interview.2 13/09/2012)
\end{abstract}

Paul wants to develop players with an exceptional 'sense' of the game. For him good or great players have the sense of the game that makes outstanding players [31]. In response to being asked what makes a good player he said that, 'Ah simple, the bloke who looks like he's got time and space to do everything, he's never cramped for room he has time to do things' (Int. 2, 13/09/2012). His criticism of over structured coaching in Australian rugby over the past fifteen years reflects how much he values players having game sense:

\footnotetext{
I find the issue with Australian rugby over the last - it has to be the last at least 10 - it could be 15 - years, the emphasis has gone off the players with a high degree of skill, making the correct decisions at the right time and doing it under pressure, that's gone away from that to pre-packaged sort of stuff (Int. 2, 13/09/2012)
} 


\section{Robert}

In all three interviews Robert emphasized strong belief in the value of respect and commitment of players that he explicitly claimed came from his background in South Africa. He prioritised a good work ethic and a respectful environment while also expecting consistently appropriate behaviour from all his players. When asked what he felt his role as a coach was he responded by saying that:

I think the biggest, if you had to ask them, any of those players it would be that hard work bares fruit. That would probably be the single most important thing that I try and instil in them, you keep working hard you'll get the benefit and also just to keep your feet on the ground and you know when you start achieving things don't become arrogant because it's a big fall from arrogancy (Int..3 22/11/2012)

These are the same values that he said characterise rugby culture in South Africa and were evident across all interviews with him during the study. The links to work ethic also featured when asked what he believes makes a good player to which he responded:

For me, it's about commitment and hard work. I would much rather play with someone who's committed and hardworking than with someone who's talented. Because the talented ones quite often sit back and depend on their talents, where the hard working guys they know they need to work hard, they're a lot fitter, you know their skills will probably never be the same as the very talented boys but they're a better player to have on your team (Int.1, 21/08/2012)

Robert thought that it was important that players enjoyed themselves and he said that he developed a 'friendly' relationship with the players. However, it was extremely important to him that they still knew he was boss and he was 'running the show'. He made a clear distinction between being liked or popular and being respected:

Even at $1^{\text {st }}$ grade we still try and make it fun for them because nobody wants to do stuff when you're not enjoying it and that's my commitment to them to make sure that all those boxes are ticked and that they enjoy, one playing rugby and that they enjoy being part of the club. But I don't try to be popular, I don't have to be popular because if you try and play the popularity game a lot of it goes out the window and that quite often prevents you from making tough decision if you try and be popular it just doesn't work. You should be respected but you don't have to be popular. Big difference! (Int.1 21/08/2012)

Similarly his views on respect and the need for a coach to have the ability to make hard decisions seem to be linked to how he was coached as a player and the importance placed on these. Additionally it seems that he articulates the taken for granted ideals of respect of coaching.

Look I think we do things a lot differently in SA, I for one look I'm a straight shooter all the players know where they stand with me. If they stuff up I'll tell them but I never pick on people, I never take someone on in front of the rest if I've got a problem I'll pull them aside and I'll have a chat to them. I mean that for me is a given that's just respect. I mean you don't be little someone in front of his teammates. But I think the biggest thing; I think - is we're straight shooters mate. I mean, if you come to SA we've grown up like that you know coaching has been like that for many, many years in SA and it will probably always be like that (Int.1 21/08/2012)

\section{Discussion}

Prior to beginning the field work there was an expectation of identifying some common themes or at least common features among the three coaches as Light and Evans [11] did. However, their beliefs about coaching and dispositions toward ways of coaching are quite different. Locating these differences in experience within three different countries and rugby cultures highlight the powerful influence of the socio-cultural context on the construction of a coaching habitus.

The coaches' three different journeys through rugby and the significant difference in context were embodied in quite different views, beliefs and inclinations. Belief in the ideals of amateurism are common across all three participants as a global influence associated with the dissemination of rugby and its amateur ideals through British colonisation and its global influence over the late nineteenth and early twentieth centuries. The development of the other features of the participants' coaching habitus identified can be located in quite specific socio-cultural contexts in three different countries. This then makes this a complex yet rich case study.

Mike's beliefs were situated in his past experiences in New Zealand within the national culture of rugby as a social subfield that profoundly shaped his beliefs about coaching:

I'm a Kiwi and in New Zealand the influence of the Maori culture on all of us and in particular on rugby. Rugby is spiritual in New Zealand, you know more than anything else it's spiritual. And when I played first XV we got our own Haka and I knew what that meant to me personally that we literally challenged the opposition. And that ritual galvanised us you know as a group and we were at one and our hearts beating simultaneously, you know during the ritual of the Haka (Int.2 13/09/2012).

Within this larger sub-field what could be seen as communities of practice [32] also seemed to play a significant part in the construction of his coaching habitus:

My heart, if you like, is still very much a part of clubs like College Rifles and Auckland University and the Blues more so than it is to be honest with Melbourne or the Rebels because this is a surrogate home for me (Int.2 13/09/2012)

The broad culture of rugby in Australia also had a durable effect on the formation of Paul's coaching habitus but it seems that it was, more specifically, a particular era in Australian rugby culture that he refers to as 'the decision making era'. This is the decision-making era in which he played for the Wallabies. He explained how the 'win percentage' for the national team prior to 1975 was no more than $40 \%$ but went up to 70 - 80\% over the 'decision-making era' between 1975 and 1995 during which:

\footnotetext{
...something was happening and evolving. Australia doesn't have a great number of players so you have to take ok we don't have a great number of players how do we get around that. So what you have to do is have great coaching...so up until 1995 we had a system in place, that was a decision making system, the players that came through that were la crème de la crème. If you look at the players, some of the greatest players that ever played in this country around 1995 went right through in that era (Int.3 29/11/2012)
}

Like Mike, Robert emphasised the differences between South Africa and Melbourne and how his values and beliefs about coaching were formed in South Africa:

There's a massive difference, it's a cultural difference in terms of commitment, commitment in SA is a lot better than it is here. We've had 
a couple of instances, not too dissimilar to other clubs in Melbourne, where now and again, we would have four guys not show up to training, $1^{\text {st }}$ grade. Two of them might send you a text, two of them you would have no idea of where they are. In SA that's unheard of, if you have to move the world and the mountains to get training you'll just do it, so the level of commitment has got to do with the culture (Int.1 21/08/2012)

\section{Conclusion}

This case study on three rugby coaches in the state of Victoria in Australia highlights the ways in which experience over time shapes beliefs about and dispositions toward coaching. It identifies features of an individual coaching habitus and suggests the ways in which the specific sociocultural settings within which they practised shaped its construction. We do not have the space here to provide more detail but we have nominated contexts of different size within which the habitus was constructed. In some cases this is a community of practice but located within larger sub-fields such as the rugby culture of a country, which, in turn is located within the overlapping fields of sport and business. This article provides a good example of how important the socio-cultural context is in the formation of beliefs and inclinations that can profoundly influence the ways in which coaches coach. It also suggests the ways in which the history of coaches experience within particular contexts are likely to influence how they interpret and use or not use innovations in coaching.

\section{References}

[1] Jones, R.L., Armour, K.M. \& Potrac, P. Understanding the Coaching Process: A Framework for Social Analysis. Quest. 54, 34-48, 2002.

[2] Bowes, I. \& Jones, R.L. Working at the Edge of Chaos: Understanding Coaching as a Complex, Interpersonal System. The Sport Psychologist. 20, 235-245, 2006.

[3] Cushion, C. Modelling the Complexity of the Coaching Process. International Journal of Sports Science \& Coaching. 2(4), 395- 401, 2007.

[4] Jones, R.L., Bowes, I. \& Kingston, K. Complex practice in coaching: studying the chaotic nature of coach-athlete interactions. In J. Lyle \& C. Cushion (Eds.) Sports Coaching: Professionalisation and Practice 2010 (pp. 15-26). London: Elsevier.

[5] Jones, R., Morgan, K. \& Harris, K. Developing coaching pedagogy: seeking a better integration of theory and practice. Sport, Education and Society. 17(3), 313-329, 2012.

[6] Nash, C. \& Collins, D. Tacit Knowledge in Expert Coaching: Science or Art? Quest. 58, 465-477, 2006.

[7] Abraham A, Collins D \& Martindale R. The Coaching Schematic: Validation Through Expert Coach Consensus. Journal of Sport Science, 24(6), 549-564, 2006

[8] Lyle, J. Sports coaching concepts: A framework for coaches' behaviour. London: Routledge, 2002.

[9] Light, R.L. opening up learning theory to social theory in research on sport and physical education through a focus on practice. Physical Education \& Sport Pedagogy. 16(4), 369-382, 2011.
[10] Christensen, M.K. "An Eye for Talent”: Talent Identification and the "Practical Sense" of Top-Level Soccer Coaches. Sociology of Sport Journal. 26, 365-382, 2009.

[11] Light, R.L. \& Evans, J.R. Dispositions of elite-level Australian rugby coaches towards game sense: characteristics of their coaching habitus. Sport, Education \& Society, 2011. DOI:10.1080/13573322.2011.593506

[12] Nash, C. \& Collins, D. Tacit Knowledge in Expert Coaching: Science or Art? Quest. 58, 465-477, 2006.

[13] Saury, J. \& Durand, M. Practical Knowledge in Expert Coaches: OnSite Study of Coaching in Sailing. Physical Education, Recreation and Dance. 69(3), 254-266, 1998.

[14] Gergen, J.K. An invitation to social construction ( $2^{\text {nd }}$ Edition). London: Sage Publications, 2009.

[15] Cushion, C.J., Armour, K.M. \& Jones, R.L. Coach Education and Continuing Professional Development: Experience and Learning to Coach. Quest. 55, 215-230, 2003.

[16] Nash, C.S., Sproule, J. \& Horton, P. Sport Coaches’ Perceived Role Frames and Philosophies. International Journal of Sports Science \& Coaching. 3(4), 535-550, 2008.

[17] Cushion, C. \& Jones, R.L. (2006) Power, Discourse, and Symbolic Violence in Professional Youth Soccer: The Case of Albion Football Club. Sociology of Sport Journal. 23, 142-161.

[18] Jones, R.L. \& Wallace, M. (2005) Another bad day at the training ground: Coping with ambiguity in the coaching context. Sport, Education and Society. 10(1), 119-134.

[19] Piggott, D. (2011) Coaches' experiences of formal coach education: a critical sociological investigation. Sport, Education and Society. 1-20.

[20] Taylor, B. \& Garratt, D. (2010) The professionalisation of sports coaching: relations of power, resistance and compliance. Sport, Education \& Society. 15(1), 121-139.

[21] Jones, R.L., Potrac, P., Cushion, C. \& Ronglan, T. (2011) The sociology of sports coaching. New York: Routledge.

[22] Langer, B. (1992) Social Theory: A guide to Central Thinkers (edited by Paul Beilharz), 70- 75 .

[23] Bourdieu, P. (1977) Outline of a Theory of Practice. (R. Nice, Trans.) London: Cambridge University Press (Original work published 1972).

[24] Crotty, M. The Foundations of Social Research: Meaning and Perspective in the Research Process. Australia: Allen Unwin, 1998.

[25] Herbert, R.J. Qualitative interviewing: The art of hearing data. California: Sage Publications, 2005.

[26] Strauss, A. \& Corbin, J. Basics of Qualitative Research: Grounded Theory Procedures and Techniques. California: Sage, 1990.

[27] Lau, R.W.K. (2004) Habitus and the Practical Logic of Practice: An Interpretation. Sociology. 38(2), 369-387.

[28] Evans, J. R. (2011) 'Elite rugby coaches' interpretation and use of Game Sense in Australia and New Zealand: An examination of coaches' habitus, learning and development', unpublished thesis, University of Sydney.

[29] Atkinson, R. The Life Story Interview. In J.F. Gubrium and J.A. Holstein (Eds.), Handbook of Interview Research: Context \& Method (pp. 121-140). California: Sage Publications, 2001.

[30] Ryan, G. (2008) The Changing Face of Rugby: The Union Game and Professionalism since 1995. Newcastle: Cambridge Scholars Publishing.

[31] Light, R.L., Harvey, S. \& Mouchet, A. Improving 'at-action' decisionmaking in team sports through a holistic coaching approach. Sport, Education and Society. 1-18, 2012.

[32] Lave, J. \& Wenger, E.. Situated learning, Legitimate peripheral participation and communities of practice. Cambridge: Cambridge University Press.(1991). 